\title{
Valparaíso: la ciudad-puerto más importante de Chile y la vulnerabilidad de su patrimonio arquitectónico a los riesgos sísmicos
}

\author{
Most important port city in Chile, Valparaiso and \\ the vulnerability of its arquitectural heritage \\ to seismic risks
}

\author{
Alfredo Sánchez M. ${ }^{*}$ y Cecilia Jiménez V.*
}

\section{INTRODUCCIÓN}

La naturaleza es capaz de provocar por sí sola desastres naturales que afectan el paisaje, así como al desarrollo económico y social de una región. La denominación de desastre natural corresponde a los fenómenos, donde el hombre no interviene directamente pero es perjudicado por los resultados del evento. Uno de los desastres, es el que se produce por el movimiento de las placas tectónicas de la Tierra que generan a través de ondas sísmicas la liberación de energía acumulada, provocando con ello los terremotos, que repercuten con mayor intensidad en el patrimonio arquitectónico de una ciudad y a veces terminan por destruir parte de su historia.

Chile por su localización geográfica en un área de intensa actividad sísmica es uno de los países más propensos a terremotos, los que ocurren con una regularidad que aún no se puede precisar. La mayoría de sus ciudades están expuestas a estos embates de la naturaleza y las más densamente

\footnotetext{
* Doctor en Geografía, Esc. Graduados, Facultad de Arquitectura, Universidad de Valpa raíso. Chile (alfredo.sanchez@uv.cl).

${ }^{* * *}$ Escuela de Arquitectura, Facultad de Arquitectura, Universidad de Valparaíso. Chile.
} 
pobladas, sufren con mayor rigor pérdidas: humanas, económicas, materiales y patrimoniales.

El artículo se refiere a la importancia que tiene los sismos como fenómeno natural en el entorno natural, sobre la identidad cultural y en el diseño de su herencia patrimonial. Se analiza la ciudad de Valparaíso, que por su emplazamiento, en parte sobre una antigua playa de arena, y por otra, cubierta por rellenos artificiales provenientes de escombros y sedimentos aportados por sus quebradas, está más expuesta a los efectos de los movimientos sísmicos. Al mismo tiempo, la ciudad creció sin planificación previa hacia el mar y también de manera espontánea hacia los cerros generando una urbanización desordenada que a pasar de ser heterogénea es unitaria, siendo los fondos de quebradas las vías naturales de accesos entre plan y cerro.

En cuanto a su desarrollo económico, la ubicación estratégica de Valparaíso lo transformó en un puerto de primer orden en las rutas oceánicas hacia el resto del continente y al hemisferio Norte. La ciudad se integró así a los más diversos mercados de la época, transformándose a mediados del siglo XIX en el primer puerto del Pacífico Sur. En el plano interno, la condición de ciudad puerto, ayuda a explicar su acelerado crecimiento poblacional y urbano donde destacan las construcciones portuarias, religiosas y defensivas.

En efecto, el puerto generó una atracción natural por las posibilidades de trabajo y las oportunidades de negocios y por ello, cada vez, más personas llegaron a establecerse en la ciudad no sólo los inmigrantes europeos, sino también población desde el interior del país, desde diversas zonas del campo que al carecer de políticas estatales se localizaron en los interfluvios (quebradas), generando así las primeras desigualdades sociales en la ciudad. La población que ocupo los cerros y terrenos altos de Valparaíso, dieron lugar a un tejido urbano orgánico, de carácter espontáneo y pintoresco.

Al mismo tiempo, la complejidad de este escenario le otorga a la ciudad una identidad propia donde los procesos históricos, las limitaciones geográficas, la originalidad de su paisaje natural, con una bahía-anfiteatro entorno al mar, más el aporte cultural de los inmigrantes venidos de Europa y la condición sísmica son los factores que han incidido directamente en la permanencia del patrimonio no sólo arquitectónico sino también urbano existente en la ciudad-puerto de Valparaíso, singularidad reconocida por UNESCO al incluir el Área Histórica de Valparaíso en la Lista del Patrimonio Mundial, en el año 2003. 
Valparaíso, entre las grandes ciudades de Chile, es sin lugar a dudas la de características más especiales, tanto por su aspecto topográfico, físico y urbanístico, como por su historia, tradiciones y patrimonio. Dicha cualidad, que le confiere la condición de realidad urbano-arquitectónica extraordinaria, ha sido descrita y comprendida como resultado del continuo proceso de ocupación del particular marco geográfico en que la población se ha ido desarrollando en el curso del tiempo (Brignardello et al. 1998).

$\mathrm{Su}$ importancia geográfica se refleja en las condiciones morfológicas que definen el paisaje natural de Chile Central, en este caso la presencia de la cordillera de la Costa, le confieren al lugar de emplazamiento de Valparaíso un grado de originalidad tal que suele asimilarse con la identidad natural que distingue a la ciudad de otras ciudades puertos (figura 1). Tiene un clima benigno y temperaturas moderadas a lo largo de todo el año, lo que se explica por la influencia de la Corriente Fría de Humboldt y de la brisa marina sobre el espacio costero local y regional (Sánchez, 2003). Dado el escenario natural que ofrecía este paisaje, la ciudad no fue objeto de una fundación, de acuerdo al modelo de las Leyes de Indias, ni de una planificación urbana previa, por el contrario se desarrollo de manera espontánea, de acuerdo a la disponibilidad espacial y a medida que aumentaba su densidad poblacional compuesta por población ru-

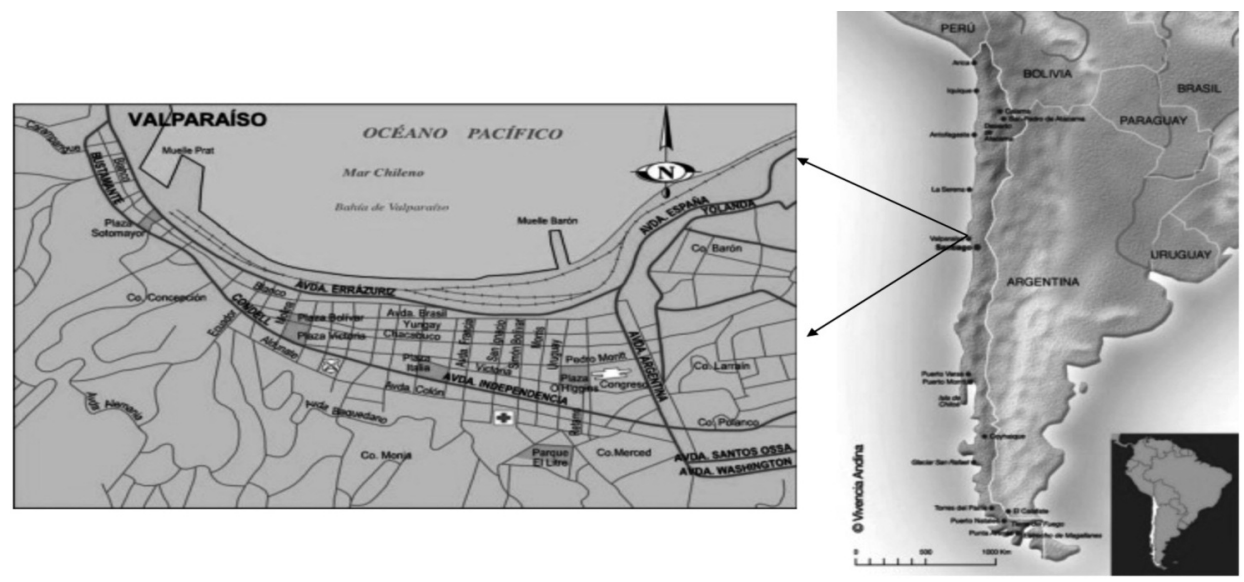


ral e inmigrantes provenientes de Europa. La opinión de arquitectos dedicados a este tema, resumen la realidad en la frase «la gente se instaló y fue haciendo el mapa de la ciudad antes de que hubiera tiempo para pensarla».

La ciudad se asienta en medio de un talud natural de la planicie costera. Su entorno natural está marcado por una cadena de cerros de dirección norte-sur y que se expanden en torno a la bahía dando forma a un paisaje que configura un anfiteatro natural, de acuerdo con las condiciones geográficas existentes en el lugar. A partir de la segunda mitad del siglo XIX se produce un movimiento migratorio de población rural hacia Valparaíso, que da paso a la ocupación de los cerros, de esta forma se creó una de las características más atrayentes de la ciudad. Al mismo tiempo, esta ocupación de espacio desde el plan al cerro trae consigo las costumbres, hábitos y formas de vida en general.

Este escenario de cerros poblado generados de manera espontánea (figura 2), condicionó el desarrollo urbano de la ciudad y al mismo tiempo fue la base de una distribución socio-demográfica claramente diferenciada entre los habitantes del plan y de los cerros. En términos patrimoniales se suele caracterizar a la ciudad más que por los edificios, en su trazado urbano irregular condicionado por la topografía de sus cerros y su escaso terreno plano con lugares singulares como ascensores, miradores y caminos empedrados. Todo esto genera un polo particular de crecimiento poblacional desde su nacimiento hasta mediados del siglo xx (Sánchez, Bosque y Jiménez, 2009).

\section{FIGURA 2}

\section{VALPARAÍSO Y SU IDENTIDAD NATURAL}

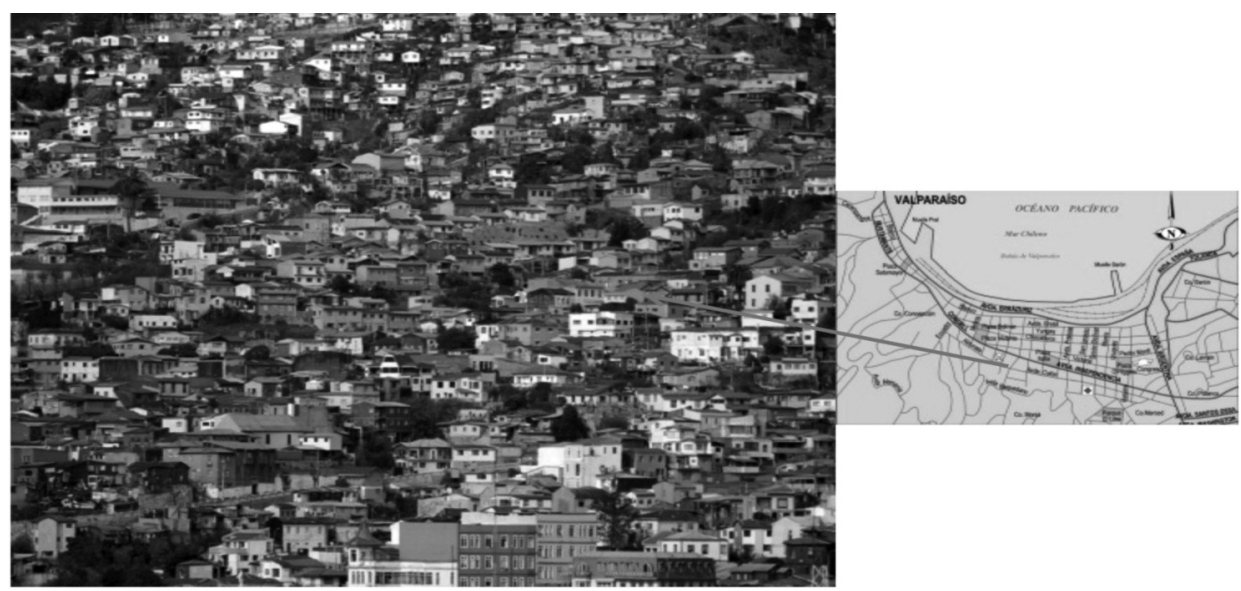

Estudios Geográficos, Vol. LXXII, 271, pp. 559-589, julio-diciembre 2011 ISSN: 0014-1496, eISSN: 1988-8546, doi: 10.3989/estgeogr.201122 
Un segundo aspecto a destacar, a nivel nacional es el auge económico que significó para Chile su independencia de la corona de España, con el modelo exportador primario se abrieron nuevos mercados a los recursos naturales que el país, en su periodo colonial enviaba sólo a la península ibérica. Esta creciente actividad mercantil del sector portuario vino acompañada de la llegada a la ciudad de comerciantes provenientes de Europa, en particular ingleses, franceses y alemanes, que junto a su actividad comercial y financiera, dejaron huellas de su permanencia, en la arquitectura y en el diseño de los edificios construidos en distintos puntos de la naciente ciudad puerto de la zona central de Chile y en particular, en la conformación urbana de los cerros Alegre y Concepción.

La presencia de diversas órdenes religiosas católicas también se hizo fuerte en Valparaíso, cabe mencionar a los mercedarios, agustinos, jesuitas, franciscanos, dominicos y los hermanos de San Juan de Dios, que se establecieron definitivamente en la ciudad y sus iglesias contribuyeron a crear el patrimonio arquitectónico religioso que posee actualmente la ciudad.

La suma de todos los acontecimientos que simultáneamente se desarrollan en la ciudad explica la presencia de una arquitectura patrimonial que presenta obras de las más variadas tipologías y estilos, aplicados a construcciones que van desde viviendas sencillas hasta los exponentes de la arquitectura monumental localizada en el sector plan de Valparaíso. En este sentido es interesante destacar que las edificaciones españolas fueron desapareciendo, por los sismos e incendios y por el rechazo que generaba en los porteños el recuerdo de la colonia, mientras la arquitectura de Valparaíso mostraba rasgos de la presencia de ingleses y franceses en la ciudad.

Otro dato a considerar es que a mediados del siglo XvI (1544), la ciudad fue declarada puerto oficial de Santiago, y con ello las manifestaciones del patrimonio portuario merecen también una mención, como ocurre con la zona de protección de la bahía (molo de abrigo), los almacenes y bodegas portuarias, más los edificios que anteceden al muelle Prat. La legislación mercantil fue pensada para hacer de Valparaíso un puerto de primer orden favorecido por su posición geográfica en la Zona Central del país y el gran empuje económico dado por la exportación de trigo chileno a California y Perú. Más tarde el gran dinamizador sería la minería del norte de Chile, especialmente el salitre. Valparaíso era la ciudad que estaba a la vanguardia de innovación, ya en 1856, la ciudad se convirtió en una de las primeras de Sudamérica en tener alumbrado a gas (Couyoumdjian, 2000).

Resulta interesante destacar el vínculo que se establece entre los componentes propios de la topografía de la ciudad y la dinámica que conllevan las activi- 
dades de una ciudad puerto, pues ayuda a comprender como Valparaíso evoluciona desde un paisaje cultural caracterizado por la presencia de caseríos, donde se instalaron las familias más acomodadas en torno a la iglesia La Matriz, a una trama urbana en constante expansión, en todo el sector plan cercano a las faenas del puerto. La actividad comercial se desarrollaba en el entorno próximo al puerto de atraque de las naves que unían la ciudad con ultramar.

Las terrazas presentan distintas extensiones de superficie y están drenadas por las aguas que provienen de los sectores más altos que fueron ocupadas escalonadamente conformando sectores geográficos específicos y diferenciados según sus características socioeconómicas y culturales. Sin embargo comparten una historia y un espacio para desarrollar una identidad local común, de tal manera que el valor patrimonial de la ciudad, no sólo tiene un componente histórico y un sentido económico, sino que va más allá, refleja el significado de una época donde la heterogeneidad de su arquitectura se observa al recorrer su plan y sus cerros.

\section{El LEGADO MIGRATORIO EN EL DESARROLLO ECONOMICO Y EL CRECIMIENTO PATRIMONIAL URBANO}

\section{La inmigración europea, la apertura comercial y el patrimonio urbano}

La economía chilena ha sido a través de su historia muy dependiente de los ciclos mundiales según el comportamiento de sus materias primas. Este vinculo con el mundo comenzó en los albores de la conquista con la minería de la plata y cobre, luego en el siglo xIx y la primera parte del siglo xx fue el salitre y para terminar el pasado siglo dependiendo fuertemente del cobre. Al mismo tiempo, Chile como país, se transformó en uno de los principales proveedores de víveres (trigo) para California durante la fiebre del oro y también a Perú a través del puerto del Callao.

La herencia que dejo la corona española con la doctrina económica mercantilista, se expresaba en que la verdadera riqueza de una nación residía en acumular el máximo posible de metales preciosos. Con esta política de crecimiento, España se reservó el monopolio comercial o exclusividad de los productos de sus colonias en América. Los principios mercantilistas continuaron en Chile, después de la Independencia de la corona, apoyada ahora por una estrategia de crecimiento basada en la exportación de materia prima, con la diferencia que ahora cada país fue soberano para decidir el volumen y destino de sus exportaciones. En esa perspectiva económica, el país recibió financia- 
miento externo venido de Europa y más tarde de Estados Unidos, para la explotación y luego exportación de sus recursos.

En cuanto a la inmigración europea, un primer tema a clarificar es que en el Océano Pacífico, ésta no tuvo las proporciones ni la fuerza que caracterizaron al mismo fenómeno en la costa Atlántica. Sin embargo, su carácter selectivo y urbano de la migración permitió que, a pesar de su disminuido volumen tuviera una repercusión importante y totalmente desproporcionada respecto a sus efectivos demográficos. La ubicación geográfica de los europeos en Chile coincide con aquellos sectores donde se concentró la actividad económica. Por tanto las ciudades de: Santiago, Valparaíso, Concepción más las zonas de explotación minera del Norte, fueron los lugares preferidos por los europeos (Garreaud, 1984).

La participación de los inmigrantes en la actividad industrial de Chile fue un factor decisivo para su posterior desarrollo. En el país, su presencia en los mercados estuvo marcada por dos sectores productivos, los recursos provenientes de la minería con sus reservas de cobre y nitratos (salitre) que generaban los ingresos que llegaban al país y en segundo término con la producción de cereales provenientes de la zona centro-sur del país. Hacia mediados de 1880, el Estado chileno asume una actitud más activa con la llegada de inmigrantes europeos para apoyar el incipiente desarrollo industrial. Hasta ese momento, el gobierno se había concentrado en atraer agricultores para ocupar los espacios vacíos de toda la zona sur del territorio que se iba incorporando a la nación. El decreto ley del 10 de octubre de 1882, creó la Agencia General de Colonización e Inmigración para Europa, con sede en Paris y Burdeos como centro de propaganda y selecci6n de los inmigrantes europeos, interesados en venir a Chile (Couyoumdjian, 1986).

En la perspectiva histórica del tema, la vinculación del país con los mercados mundiales hizo posible la modernización de las técnicas agrícolas, el despliegue del espíritu aventurero de los empresarios mineros y la llegada de inversionistas extranjeros. Una vez consolidada la independencia, la política económica de apertura de los recursos naturales hacia los mercados mundiales, dieron forma a un nuevo modelo capitalista, liderado por Gran Bretaña, que emergía como la mayor potencia económica de la época: el aporte que significó la creación de bancos, con lo cual surgió una alternativa de créditos más estructurada y fluida que la existente hasta ese momento. Las instituciones financieras privilegiaron las inversiones de corto y mediano plazo y apostaron en los sectores del comercio y la minería.

En cuanto a su dinámica social el país enfrentó la Independencia con una sociedad netamente agraria, con una producci6n artesanal estacionaria y po- 
bre y que en ningún caso podía originar un proceso de crecimiento y desarrollo, de tal manera que al momento que comienza a manifestarse la llegada de la inmigración europea en Chile, se advierte su presencia en el desarrollo del sector industrial. Mientras que la actividad minera y la agricultura, a través de los molinos y las curtiembres, acogen especialmente a los ingleses, quienes impulsaron una serie de actividades pioneras en materia de innovación industrial (Estrada, 1993). Muchos de los molinos fueron creados no por hacendados, sino por marinos y comerciantes, quienes desde Valparaíso se fueron a instalar a la zona sur del país.

Como se puede observar, esta nueva tendencia se caracterizó por localizar su red de conexiones en las ciudades puertos que ofrecían, a los inversionistas extranjeros las ventajas necesarias para localizar la distribución de sus productos y por ello recibieron importantes aportes, que de paso favorecieron un proceso de urbanización y modernización de dichas ciudades.

TABLA 1

NÚMERO DE EXTRANJEROS CENSADOS EN

EL DEPARTAMENTO DE VALPARAÍSO (1875-1952)

\begin{tabular}{lrrrrrrrr}
\hline & \multicolumn{8}{c}{ Años } \\
\cline { 2 - 9 } Nacionalidad & 1875 & 1885 & 1895 & 1907 & 1920 & 1930 & 1940 & 1952 \\
\hline Alemanes & 1.134 & 1.165 & 1.396 & 2.055 & 1.440 & 1.503 & 2.162 & 1.568 \\
Franceses & 986 & 819 & 1.097 & 1.003 & 791 & 549 & 377 & 375 \\
Españoles & 346 & 562 & 1.317 & 3.463 & 3.496 & 3.040 & 3.233 & 2.836 \\
Británicos & 1.785 & 1.478 & 1.974 & 2.053 & 1.799 & 1.322 & 693 & 419 \\
Italianos & 807 & 1.449 & 2.264 & 2.985 & 2.837 & 2.834 & 2.848 & 2.632 \\
Otras & & & & & & & & \\
Nacionalidades & 1.863 & 2.189 & 2.252 & 3.071 & 3.080 & 4.351 & 4.351 & 4.762 \\
\hline TOTAL & 6.921 & 7.662 & 10.302 & 14.630 & 13.443 & 13.664 & 13.664 & 11.592 \\
\hline
\end{tabular}

Fuente: Censos de la República de Chile, según años indicados.

En cuanto a la arquitectura de la ciudad, la historia urbana registra la presencia cultural europea casi desde la génesis de Valparaíso. Su patrimonio está muy unido al desarrollo cultural de sus habitantes, lo que se ve reflejado en su bahía con un anfiteatro que conforma un paisaje cultural con características 
históricas y arquitectónicas propias y relevantes, donde cada zona muestra una homogeneidad de edificaciones que dan pauta a la memoria colectiva de su población (Waisberg, 1996).

En este escenario de equilibrio entre la topografía de sus cerros y la arquitectura que desafía la gravedad, toma fuerza la modernidad de las construcciones que introducen ingleses, franceses y alemanes, para intentar recrear en Valparaíso, sus tradiciones y sus propias costumbres (ver figura 3). Además de los países mencionados, durante el siglo XIX se completa con inmigrantes de naciones mercantiles Holanda, Italia y Estados Unidos, todos atraídos por el comercio y las oportunidades que ofrecía el mayor puerto de hemisferio sur (ver tabla 1). Todos ellos llegaron a radicarse en Valparaíso como emplea-

\section{FIGURA 3}

\section{EQUILIBRIO ENTRE PLAN Y CERRO CON LO TRADICIONAL Y MODERNO}

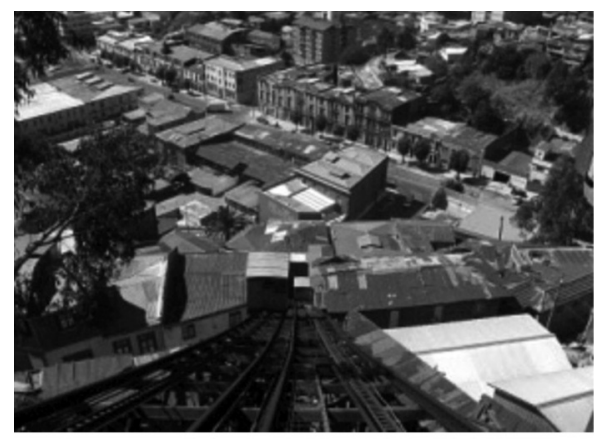

Ascensor Cerro Monjas

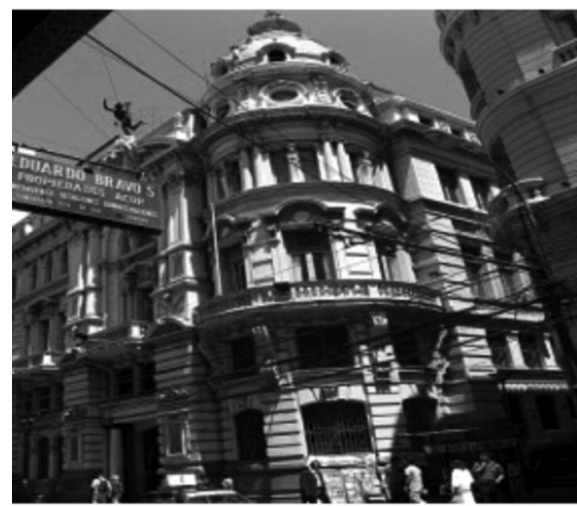

Edificio Diario El Mercurio

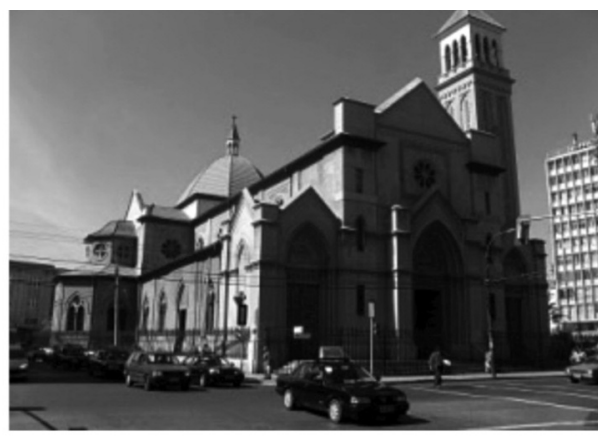

Iglesia Catedral

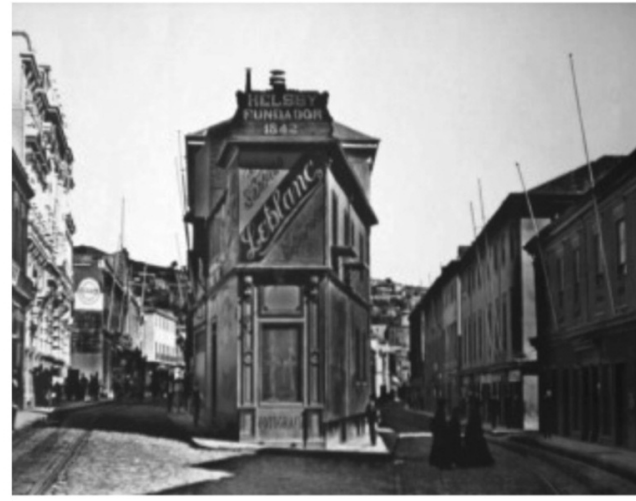

Sector Puerto: Calle Prat 
dos y agentes de las grandes de las grandes casas comerciales o como simples comerciantes, pero en general en actividades ligadas a las actividades portuarias. Esta dinámica poblacional se mantuvo hasta mediados de la década del siglo Xx.

A partir de la primera mitad del siglo xIx, la colonización extranjera provocó la primera urbanización en los cerros Alegre y Concepción, caracterizados por calles empedradas, alumbrado a gas y la presencia de los ascensores, único medio de conexión entre el sector plan y los cerros de la ciudad (1883). Los inmigrantes ingleses, alemanes e italianos que llegaron a Valparaíso dieron forma a barrios equipados según las necesidades, construyendo la Iglesia Anglicana de San Pablo, Iglesia Evangélica Alemana, Iglesia San Luis Gonzaga, Hospital Alemán, y numerosas viviendas diseñadas de acuerdo con sus patrones europeos (ver figura 4) (Jiménez, 2000).

FIGURA 4

\section{CERRO ALEGRE Y SU HERENCIA PATRIMONIAL}

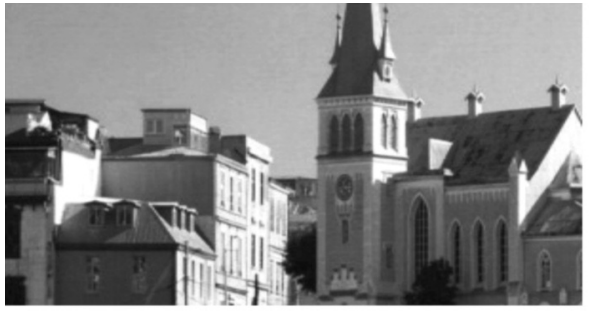

Iglesia Evangélica Alemana

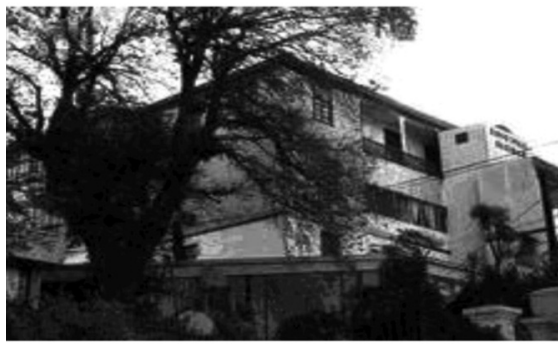

Hospital Alemán

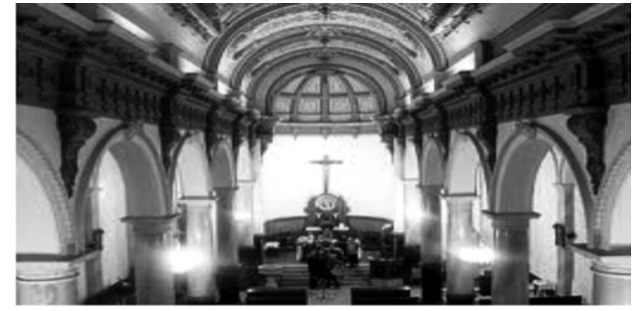

Iglesia San Luis Gonzaga

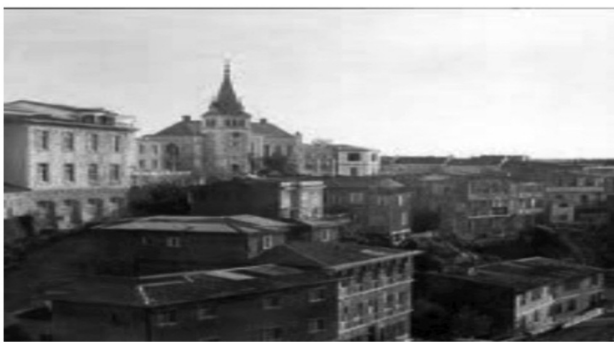

Barrio Urbano Cerro Alegre

Estudios Geográficos, Vol. LXXII, 271, pp. 559-589, julio-diciembre 2011 ISSN: 0014-1496, eISSN: 1988-8546, doi: 10.3989/estgeogr.201122 


\section{La ciudad-puerto de Valparaíso un polo de desarrollo comercial}

Consolidada la independencia nacional, momento en que el país inicia una política de apertura económica ofreciendo sus recursos básicos a los mercados de Europa y luego a Estados Unidos, la ciudad se convirtió en el emporio comercial del Pacífico Sur, dado que todas las naves encontraban en Valparaíso un puerto seguro para almacenar y redistribuir sus mercaderías. Junto con las bodegas para almacenar combustibles y mercaderías se sumaban remolcadores, grúas, lanchas a vapor, depósitos flotantes y diversos medios que facilitaban la carga y descarga de mercadería de tal modo que desde los barcos los productos eran trasladados al ferrocarril para ser distribuidos a través del país (Aguirre, 1946).

Es interesante insistir en la importancia estratégica que tuvo la situación geográfica de la ciudad dentro del espacio comercial que se extiende por la costa occidental de Sudamérica desde Panamá hasta el Cabo de Hornos. Esta área, que incluye parte de Colombia, Ecuador, Perú, Bolivia y Chile, es la que los extranjeros llamaban la West Coast.

Cuando los comerciantes británicos empezaron a incursionar en la colonia de la corona española, en la primera década del siglo XIX, el centro de operaciones natural fue el puerto de Buenos Aires. Pero, con el tiempo se impuso la ubicación geográfica, dado las dificultades para penetrar por tierra al interior y alcanzar las costas del Pacífico, en consecuencia era más práctico establecer una base en la costa occidental de Sudamérica. Gracias a las facilidades brindadas por el gobierno republicano de Chile, Valparaíso pasó a ser el primer puerto del Pacífico Sur, a ello contribuyo la derrota de la Confederación PerúBoliviana (1840), que dio paso a que la ciudad se consolidara como el puerto más importante de la costa oeste del Pacífico, después del poderoso puerto de San Francisco en California, Estados Unidos. Inicialmente las transacciones salitreras se realizaban en el Callao, Perú, pero este puerto comenzó a perder injerencia comercial a favor de Valparaíso, ya que numerosas empresas inglesas se establecieron allí, dado la mayor seguridad social y política que le ofrecía el país (Villalobos, 1986).

A escala nacional, el primer polo de desarrollo comercial del país creció en torno a Valparaíso, debido a su posición estratégica en la ruta Atlántico-Pacífico y su auge se mantuvo hasta la apertura del Canal de Panamá en 1914. En consecuencia, era el puerto de embarque para los productos mineros del Norte Chico y para el trigo proveniente del Valle Central. La ciudad se convirtió en la principal entrada de extranjeros especialmente a partir de 1820, cuando se intensifica la presión comercial europea hacia Chile como resultado 
de la Independencia y de la emigración provocada por las guerras napoleónicas. Hacia 1832, el número de barcos que recalaban era de 275, en dos años aumento a más de 400 navíos. De esta manera la mercancía movilizada entre 1832 y 1834 por el puerto se acrecentó en un $400 \%$

En 1822, Lord Cochrane trae a Valparaíso el Rising Star, primer buque a vapor, abriendo así vínculos comerciales entre el gobierno de Chile y el Reino Unido. La influencia inglesa empezaba a tener una importante presencia, lo que motivó a la escritora británica María Graham, que avecindada en el puerto señalaba: «las tiendas inglesas son las más numerosas, la mercería, la loza y los géneros de lana y algodón son los artículos principales. En todas las calles se ven sastrerías, zapaterías, talabarterías y posadas inglesas, y son sorprendentemente numerosas las personas que aquí hablan inglés» (Graham, 1970).

En términos demográficos, Valparaíso se transformó en un período relativamente corto, en un verdadero centro comercial de la costa occidental de Sudamérica, lo que atrajo un flujo importante de población, el número de sus habitantes se triplicó en menos de 10 años, de 5 mil habitantes en 1810, pasa a 40 mil en 1842; en 1865 su población era de 70.438 habitantes y en 1875 alcanza a 97.737, para llegar en 1885 a 104.952 habitantes de los cuales el $20 \%$ eran extranjeros, más una gran cantidad de población flotante. En efecto, atraídos por las posibilidades de trabajo y las oportunidades de negocios, cada vez más personas llegaban a vivir a la ciudad. En el caso de los extranjeros la mayoría eran burgueses acostumbrados a los negocios y en ese sentido marcaron la pauta a la futura aristocracia de Valparaíso. La ciudad, muestra, como sociedad, un aspecto más proclive a la modernización, frente al resto del país.

En cuanto a la dinámica del sector empresarial, el foco más innovador se ubicó en torno a las agencias locales de las casas comerciales británicas. La presencia de estos comerciantes fue el eje crucial en torno al cual giró la integración de la economía nacional al comercio mundial. De la corriente de inmigrantes llegadas a Valparaíso, corresponde a los ingleses abrir los mercados nacionales, pues tenían el acceso a las fuentes de créditos y estaban en condiciones de aprovechar tanto el flujo de importaciones como el de exportaciones.

El grupo de grandes firmas importadoras y exportadoras, casi todas extranjeras, principalmente inglesas, alemanas y norteamericanas, conformaban lo más granado de lo que se ha dado en llamar el «alto comercio» de Valparaíso, que incluía a un total de 233 casas importadoras y 97 gerencias comerciales, además de 36 almacenes mayoristas, 84 bodegas públicas, 62 almacenes de abarrotes y otros, 48 escritorios comerciales, 18 casas de consignaciones y 6 depósitos de calzado (Edwards, 1963). 
En cuanto a las empresas comerciales alemanas, una de las primeras y más importantes fue Vorwerk y Cía., cuyos orígenes se remontaban a 1846. Casi tan antigua era Weber \& Cía., establecida a mediados de la década de 1850. En cambio, la casa Gildemeister, creada inicialmente en el Perú y con intereses en Tarapacá desde los años 1860, abrió sus oficinas en Valparaíso en 1912. A esta lista se puede agregar una firma germano-chilena, Saavedra Benard y Cía. fundada en 1886, cuyos socios hacia 1914 se repartían entre Hamburgo y Valparaíso (Escobar, 1926).

En la actualidad algunas de las edificaciones patrimoniales construidas por éstos prestigiosos extranjeros, han sido restauradas con otros fines y han cambiado su giro comercial, como ocurre con la propiedad que hoy ocupa un sofisticado hotel boutique de Valparaíso, en calle Higueras 133, Cerro Alegre; que en 1830 fue la residencia de la familia del ingeniero naval Alemán, Federico Corssen Decher, que asentó en la ciudad a mediados del siglo XIX, y tuvo

\section{FIGURA 5}

\section{EDIFICACIÓN PATRIMONIAL: RESIDENCIA DE LA FAMILIA CORSSEN}

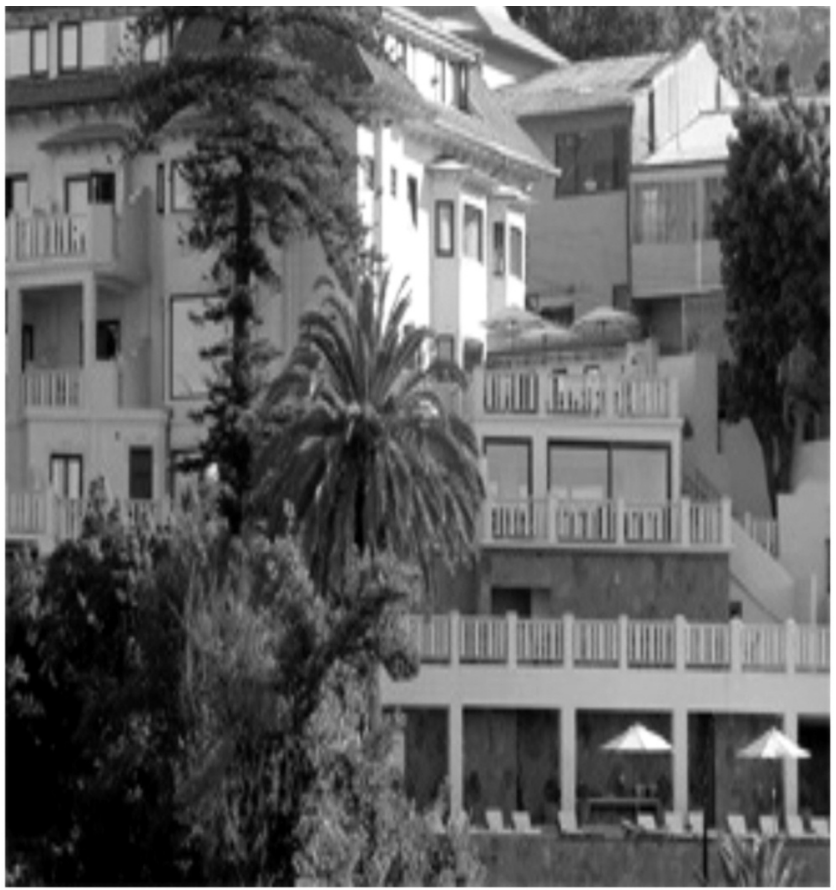

Estudios Geográficos, Vol. LXXII, 271, pp. 559-589, julio-diciembre 2011 ISSN: 0014-1496, eISSN: 1988-8546, doi: 10.3989/estgeogr.201122 
gran presencia en la construcción del dique Valparaíso II. Esta familia también estuvo asociada a la riqueza del salitre y luego a la historia de Valparaíso, como accionistas de los astilleros Las Habas, donde hoy día opera ASMAR (figura 5).

De las firmas estadounidenses en Valparaíso, las más prominentes eran la casa Grace y Wessel Duval \& Cía. La primera, que abrió su oficina en Valparaíso en 1880 durante la Guerra del Pacífico, había nacido a partir de los negocios en el Perú de William R. Grace, un irlandés nacionalizado norteamericano; la última era la sucesora de Augustus Hemenway, que se había iniciado en el comercio entre Boston y Valparaíso a fines de los años 1820.

En el sector financiero, la institución bancaria Banco Anglo-Sudamericano nació muy ligada al quehacer económico nacional, se creó en 1889 como Banco de Tarapacá \& Londres a fin de participar en las negociaciones salitreras entre Chile y Gran Bretaña, especialmente las dirigidas por su fundador John North. Comenzó con sucursales en Valparaíso, Iquique y Pisagua, para fusionarse más tarde con el banco Anglo Argentino (1901).

El comerciante inglés no se limitó a actuar de intermediario, sino que contribuyó a impulsar y desarrollar la capacidad productiva local a fin de satisfacer la demanda de minerales de los mercados extranjeros. Hacia 1820, al menos 12 firmas inglesas tenían sucursal en Valparaíso. La consecuencia de ello fue un proceso incipiente de transferencia de tecnología en la metalurgia y en la agricultura y el aumento de las exportaciones hacia Gran Bretaña (Lagos, 1966). En 1858 se crea en Valparaíso la primera Cámara Chilena de Comercio, contando para ello con la apreciable disposición de comerciantes británicos. La Marina Mercante recibe un impulso vital, con la creación de una línea de vapores entre Valparaíso y El Callao (Perú), creada principalmente con capitales ingleses. Esta compañía origina la famosa Pacific Steam Navigation Company, con rutas regulares entre Valparaíso y Liverpool en Inglaterra (figura 6).

Las ventajas comparativas para relacionarse con el extranjero y resto del país privilegiaron su ubicación para el desarrollo industrial. A fines del siglo XIX, Valparaíso, reunía un importante número de industrias que en el plano comparativo muestran un nivel de desarrollo técnico más avanzado que el resto del país incluyendo, la ciudad de Santiago. Se debe señalar también que en una primera percepción de las características de estas industrias es que mayoritariamente pertenecían a extranjeros. Lo mismo ocurre con la mano de obra especializada que muestra un predominio de la presencia extranjera.

En el sector industrial destaca la Compañía Chilena de Tabacos S.A., su historia se remonta a 1909, cuando un empresario español, Fernando de la 
Figura 6

CRECIMIENTO DEL PUERTO DE VALPARAÍSO

Puerto de Valparaíso 1850

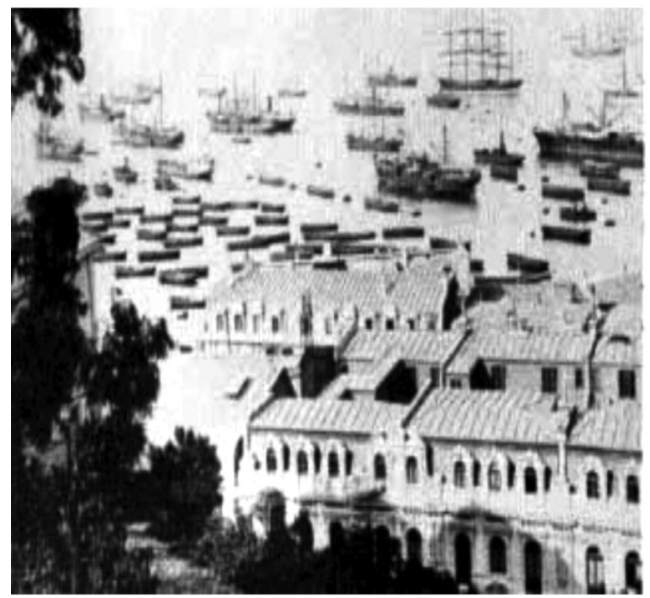

Puerto de Valparaíso 2010

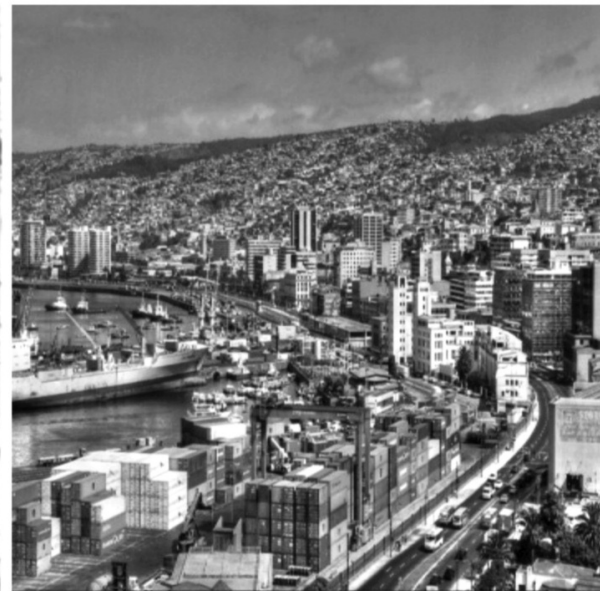

FIGURA 7

ARQUITECTURA INDUSTRIAL DE LA CIUDAD

Banco Anglo-sudamericano

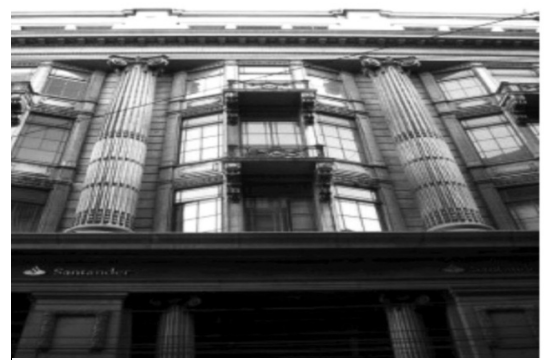

Compañia Chilena de Tabacos

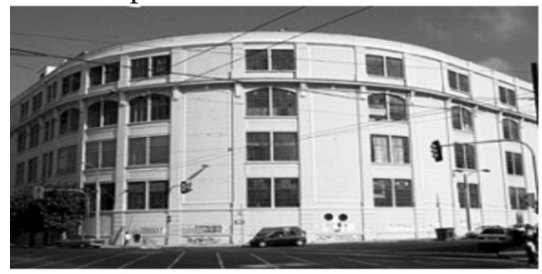

Banco Alemán Transatlántico (1912)

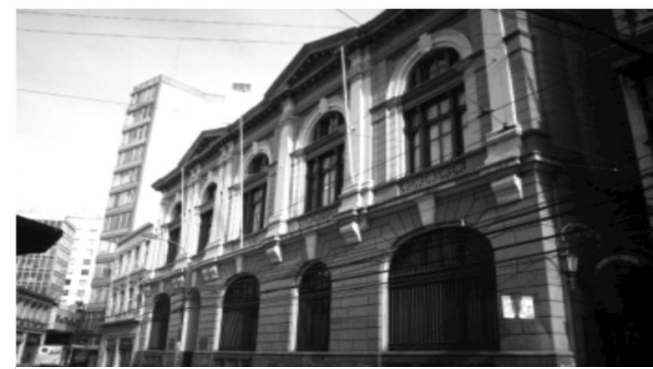

Palacio Subercaseaux

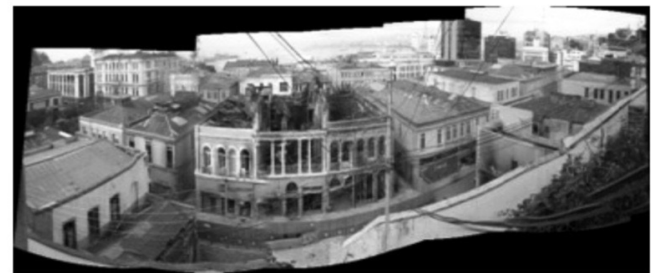

Estudios Geográficos, Vol. LXXII, 271, pp. 559-589, julio-diciembre 2011 ISSN: 0014-1496, eISSN: 1988-8546, doi: 10.3989/estgeogr.201122 
Rioja logró reunir ocho fábricas tabacaleras en una sola empresa. Los talleres fueron equipados con la maquinaria más moderna de la época para fabricar y envasar cigarrillos, quedando la empresa a la altura de las más avanzadas del continente. Luego de un período de fuerte competencia con la multinacional British American Tobacco (BAT) se produjo la fusión entre ambas empresas en el año 1936, siendo BAT el accionista mayoritario, asumiendo el control de la empresa. Durante el siglo xx, Chiletabacos dominó el mercado nacional casi de manera monopólica. La comercialización de su producto, quedo en manos de la Sociedad Comercial Chiletabacos de propiedad de la misma empresa.

\section{La colonia inglesa y su aporte al desarrollo económico y arquitectónico}

En cuanto a las relaciones comerciales y diplomáticas con Gran Bretaña, Chile siguió una línea similar a la de otros países del continente. Las relaciones diplomáticas se oficializan en el año 1823 y el reconocimiento formal en 1830. Un segundo paso diplomático importante para fortalecer el intercambio comercial fue en 1852 con la supresión recíproca de impuestos diferenciales en los puertos de ambos países lo que facilitó el comercio y navegación entre ambas naciones.

Los productos chilenos con mayor demanda desde la Isla fueron: cobre, salitre, lanas, cuero y guano. El caso del cobre y salitre merecen destacarse por las fuertes inversiones británicas en el sector, lo que facilitó la creación de fundiciones de cobre en los alrededores de la ciudad de Coquimbo ${ }^{1}$. En 1850, Chile producía el $40 \%$ del cobre mundial (tabla 2). Con respecto al salitre, al término de la Guerra del Pacífico contra la Confederación Perú-Bolivia (1983) el salitre que llegó a ser la primera fuente de ingresos del país y a la vez, centro de nuevas inversiones inglesas en Chile (Cavieres, 1988).

En síntesis las inversiones de capital británico se concentraron en el sector minero y en la producción de productos derivados de los recursos naturales del país, siendo la ciudad puerto de Valparaíso el centro de las oficinas de todas las inversiones y productos elaborados provenientes de Gran Bretaña con destino a Chile. En consecuencia, la ciudad cumplió una función estratégica en las comunicaciones de Gran Bretaña con sus intereses en ultramar. Dentro de este contexto, se entiende el interés de William Wheelright por establecer una línea de vapores en el Océano Pacífico con sede en Valparaíso, y más tarde constituyó la base de la marina mercante nacional.

\footnotetext{
${ }^{1}$ La ciudad de Coquimbo queda a $460 \mathrm{~km}$ al norte de Santiago de Chile.
} 
TABLA 2

PRINCIPALES EXPORTACIONES BRITÁNICAS DESDE CHILE. (PUERTO DE VALPARAISO) EXPRESADOS EN VALORES OFICIALES E IMPORTANCIA PORCENTUAL DE CADA ITEM(1826-1840)

\begin{tabular}{crrr}
\hline \multirow{2}{*}{ Productos } & $\mathbf{1 8 2 6 - 1 8 3 0}$ & $\mathbf{1 8 3 1 - 1 8 3 5}$ & $\mathbf{1 8 3 6 - 1 8 4 0}$ \\
\hline cobre (£) & 128.734 & 102.420 & 172.081 \\
(\%) & 36.70 & 25.73 & 22.10 \\
Cueros (£) & 103.583 & 68.923 & 34.272 \\
(\%) & 29.53 & 17.31 & 5.07 \\
Salitre (£) & 303 & 71.080 & 111.200 \\
(\%) & 0.08 & 17.86 & 16.45 \\
Lana (£) & & 7.612 & 70.706 \\
$(\%)$ & & 10.46 & 3.63 \\
Corteza de tintura (Perú) (£) & & 55.223 & 65.183 \\
Guano (£) & & 13.87 & 9.64 \\
$(\%)$ & & 296.113 \\
Otros (\%) & & \\
\hline
\end{tabular}

Fuente:Foreign Office. Customs and excise, vol. 4, 15 a 45.

Inicialmente la colonia británica compuesta por ingleses, galeses, escoceses e irlandeses llegaron a ser más de 20.000 en el apogeo del puerto de Valparaíso y había un millar más repartido por el resto del país, principalmente durante la bonanza del salitre a fines del siglo xIx y comienzos del siglo xx. La demanda por salitre creció de manera explosiva y produjo un movimiento inusitado de la economía, las exportaciones salitreras constituyeron el área más importante de la economía chilena y contribuyó a modernizar la hasta entonces precaria infraestructura del resto del país. La presencia británica fue decisiva para entender el auge comercial y urbano de la ciudad. Hacia 1890, a la ciudad llegaban unos 190.000 extranjeros, de los cuales 20.000 eran ingleses y el resto de repartía en distintas nacionalidades todas provenientes de Europa.

La burguesía británica que llegó a Valparaíso vio en su nuevo domicilio una oportunidad para hacer riquezas sin perder sus tradiciones y testimoniar de alguna manera la importancia que poseía Inglaterra en la economía internacional. Los barrios de la colonia eran una réplica de su tierra natal, se trajeron sus cigarros, sus ropas, el té, practicaron sus deportes y construyeron sus hogares 
FIGURA 8

CERRO ALEGRE Y CONCEPCIÓN
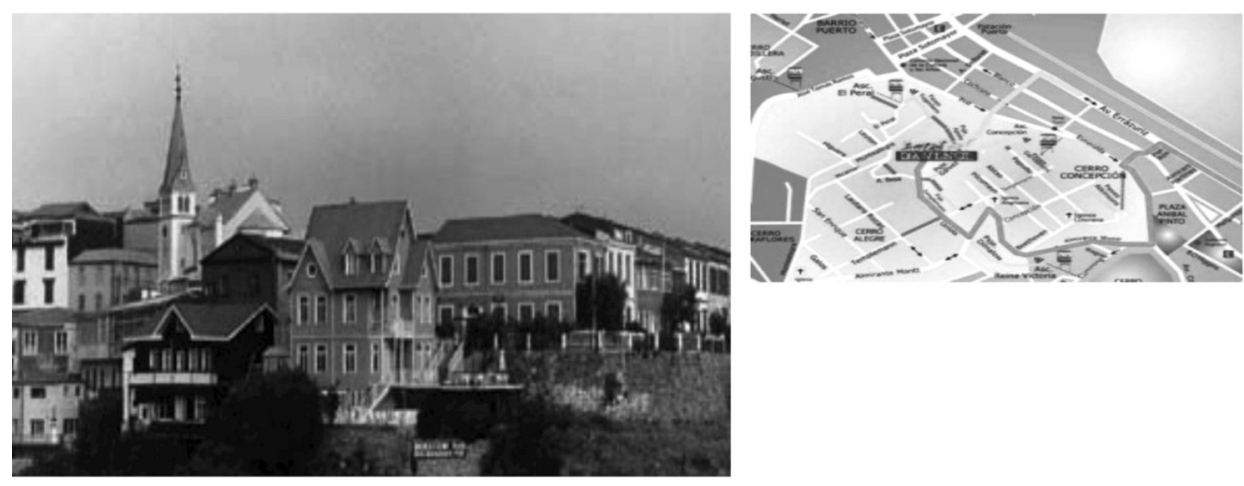

siguiendo el tradicional estilo original. La arquitectura de Valparaíso tiene una apreciable influencia de estilos europeos, en especial los edificios públicos, los locales destinados al comercio y casas particulares de la alta sociedad.

En términos de ubicación geográfica, en el Cerro Alegre (conocido como Merry Hill) era una especie de ghetto británico. Sus casas de madera, la mayoría de dos pisos, colores sobrios y sus jardines ornamentales, se diferenciaban de las tradicionales quintas del barrio, herencia de la colonia española (figura 8).

La numerosa colectividad británica concentrada fundamentalmente en el comercio exterior se agrupó en la Cámara Británica de Comercio que se fundó en 1917 con la participación de aproximadamente 30 empresas, entre las cuales figuraban los bancos y casas comerciales reseñadas, conjuntamente con otras importantes firmas tradicionales del puerto.

La presencia británica en el desarrollo económico de Valparaíso inicia su decadencia con el estallido de la Primera Guerra Mundial, Gran Bretaña, para afrontar los gastos del conflicto retira paulatinamente sus inversiones en la ciudad y en el país. Como consecuencia de lo anterior se disminuyó el volumen de las inversiones y actividades en el norte de Chile como también ocurrió con el resto de los negocios lo que presagiaba la posterior crisis económica de los años 1929 y 1932, y aunque hay casos destacados de firmas británicas que aún se mantienen operativas, en ningún caso con la relevancia que tuvieron en la época que Gran Bretaña mantenía una hegemonía como primera potencia económica mundial, como es el caso de la Agencia Naviera de George C. Kenrich y Cía. 
La incidencia de los terremotos en el Patrimonio arquitectónico y urbano de Valparaíso

Los cíclicos y frecuentes terremotos y salidas de mar, constituyen riesgos naturales datados en la historia de Valparaíso, desde su descubrimiento en 1536 hasta estos días revelan una vulnerabilidad en sus construcciones y un riesgo latente para su población. Esto explica porqué Valparaíso no cuenta, en su patrimonio arquitectónico con una arquitectura colonial, pudiendo mencionarse los terremotos de los años 1730, 1751 con salidas de mar que devastaron el villorrio original y al inicio del siglo xx, el sismo del año 1906, en el cual la ciudad resultó totalmente destruida y con más de tres mil muertos. Los más recientes de 1965, 1971, 1985 y el de febrero del presente año, también provocaron daños y un grave deterioro al patrimonio construido, particularmente en los Monumentos Histórico religiosos de mediados y fines del siglo XIX (figura 9).

Las consecuencias que estos terremotos cíclicos tienen sobre la arquitectura patrimonial de la ciudad-puerto, así como sobre su trazado urbano se pueden analizar a partir de los procesos históricos y de la configuración geotopográfica de su bahía.

En el contexto histórico, se observa que la acción sísmica ha impedido la permanencia de la arquitectura colonial en el sector Puerto de Valparaíso, perdurando sólo las edificaciones correspondientes al periodo de la mitad del siglo XIX. Por otra parte, se aprecia la evolución sistemática de las técnicas constructivas en los diferentes períodos de crecimiento de la ciudad, que van desde las propias del adobe colonial hasta la incorporación del hormigón armado, desde principios del siglo xx.

\section{FIGURA 9}

\section{EFECTOS DEL TERREMOTO DE 1906}
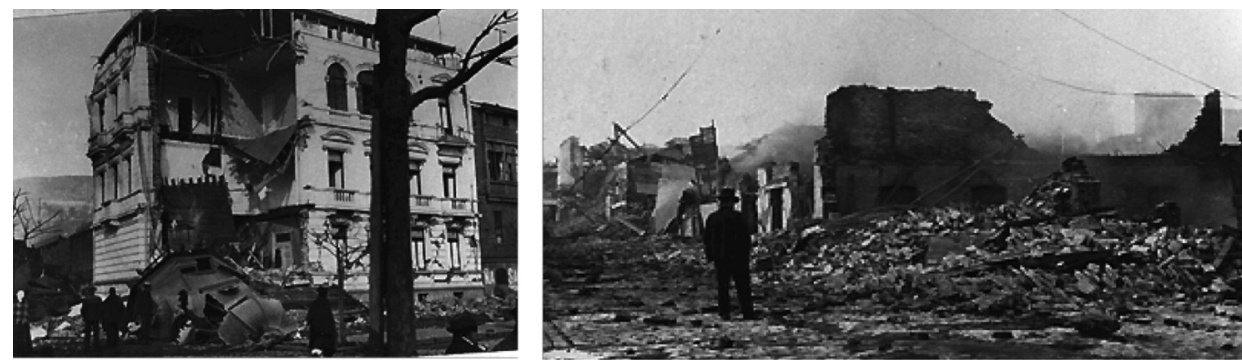

Estudios Geográficos, Vol. LXXII, 271, pp. 559-589, julio-diciembre 2011 ISSN: 0014-1496, eISSN: 1988-8546, doi: 10.3989/estgeogr.201122 
En el plano topográfico, la particular geografía natural de la bahía también va siendo afectada por los terremotos a través de la historia. Originalmente a la llegada de los españoles, la bahía estaba formada por dos sectores muy bien delimitados:

- el Puerto con un escaso terreno plano, rodeado por una cadena de cerros y

- el Almendral que correspondía a una extensa y arenosa playa, ambos sectores separados por un arrecife denominado el Peñón del Cabo que se adentraba en el mar e impedía el paso por el borde mar y obligaba a una conexión entre ellos a través de los cerros (ver figura 10 ).

Ambos sectores se consolidan a partir de las instalaciones religiosas entorno a la Iglesia La Matriz en el Puerto y a la instalación Mercedaria en el Almendral (Waisberg, 1992).

FIGURA 10

ARRECIFE PEÑON DEL CABO
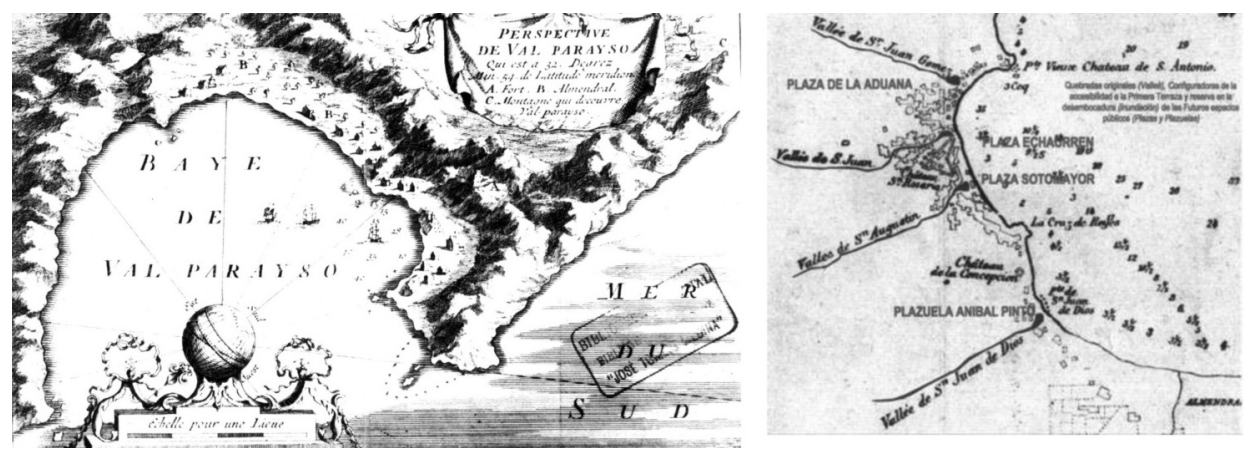

La vida de la ciudad se desarrolla por más de trescientos años en el sector Puerto, dado que el Peñón sólo es dinamitado en la primera mitad del siglo XIX, iniciándose a partir de ese momento el proceso de configuración planimétrica del borde de la ciudad que existe hoy. Serán justamente los escombros producidos por los edificios afectados por los terremotos, los que sumados a barcos encallados, escarpes de los cerros ejecutados por el hombre para ampliar el área plana de la ciudad y la erosión propia de los sectores en pendiente y su deslizamiento a través de las quebradas, los que incidirán en la Traza Urbana y el perfil definitivo del borde, que tiene la ciudad de Valparaíso (figural1). 
FIGURA 11

PLANO BAHÍA DE VALPARAÍSO PRIMERA MITAD DEL SIGLO XIX
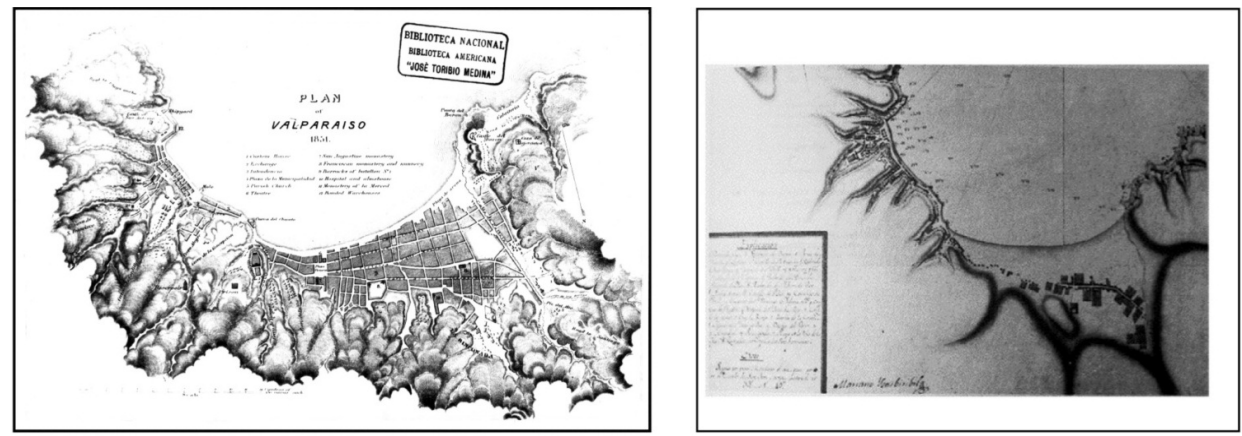

La ciudad da cuenta así de un proceso en que las condicionantes históricas y la identificación de los rasgos generados en el proceso urbano que permanecen hasta hoy, contribuyen a determinar que la traza primitiva es el elemento auténticamente patrimonial que conserva Valparaíso (Morton, 1922).

Junto con lo anterior, las diversas calidades de suelo influirán también en el grado de daños sobre el patrimonio arquitectónico, observándose las edificaciones más afectados por los terremotos, en el barrio arenoso del Almendral que han sido demolidas total o parcialmente, en contraposición a edificios del Área Histórica del barrio Puerto construidos en el mismo período, en el plan de la ciudad muy cercano al borde los cerros sobre un material rocoso, que permanecen aún en pie y en buenas condiciones (Waisberg y Martínez, 1969).

Los sucesivos terremotos se ven reflejados en las diferentes técnicas constructivas, aplicadas a la arquitectura Historicista ecléctica de la ciudad. El adobe macizo dispuestos de soga en muros de gran espesor y baja altura, cimientos y sobrecimientos de piedra, madera en techumbres y tejas de arcilla en cubiertas, demuestran un sabio manejo del material y técnicas que les han permitido permanecer hasta hoy, como son la Iglesia La Matriz (1842 cuarta versión), generadora del núcleo origen del poblamiento inicial de la ciudad y la Casa de Juan Mouat en el Cerro Cordillera (1844) respondiendo ambas a este sistema constructivo, aunque con proporciones volumétricas distintas. Son escasos los ejemplos de arquitectura civil en adobe que aún persista a excepción de algunas viviendas en los cerros más antiguos (ver figura 12).

La segunda mitad del siglo XIX, acoge el fervor religioso católico y las primeras incursiones protestantes, construyéndose gran cantidad del patrimonio arquitectónico religioso reconocido hoy, con sistemas constructivos que van 


\section{FIGURA 12}

IGLESIA LA MATRIZ CASA DE JUAN MOUAT CERRO CORDILLERA
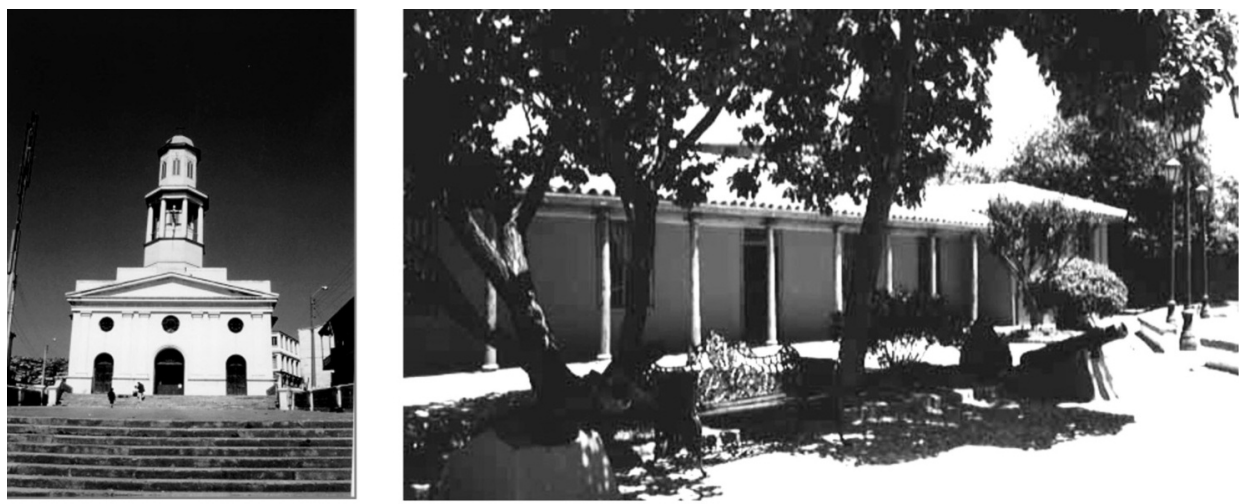

evolucionando del adobe a las albañilerías de ladrillo en muros estructurales, cortafuegos y contrafuertes del mismo material en obras de mayor envergadura, como las tipologías religiosas, bancarias, institucionales, hoteleras. En todas ellas comienzan a intervenir profesionales arquitectos, constructores e ingenieros, muchos de ellos extranjeros avecindados en el sector Puerto, tales como John Livingstone, John Brown, Ferhman o Burchard. A modo de ejemplo se puede señalar el edificio de la antigua Aduana en plaza Wheelright, la iglesia de los Doce Apóstoles en Av. Argentina (1868) o la iglesia de los Sagrados Corazones en calle Independencia (1868) (ver figura 13).

FIGURA 13

ARQUITECTURA PATRIMONIAL CON MUROS DE ALBAÑILERÍA DE LADRILLO

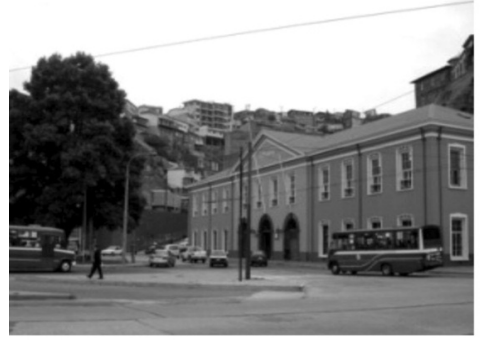

Edificio Plaza Aduana

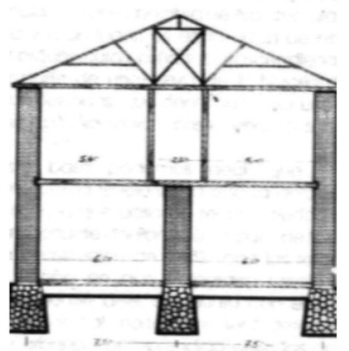

Corte

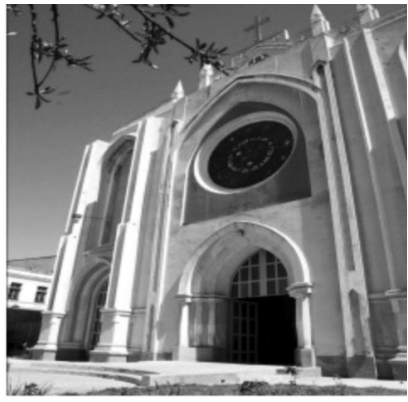

Iglesia Doce Apóstoles

Estudios Geográficos, Vol. LXXII, 271, pp. 559-589, julio-diciembre 2011 ISSN: 0014-1496, eISSN: 1988-8546, doi: 10.3989/estgeogr.201122 
Cabe señalar que estos mismos inmigrantes extranjeros se establecerán en los cerros Alegre y Concepción, constituyendo la primera ocupación en forma planificada, con urbanizaciones pioneras en cuanto a la instalación de agua potable alumbrado a gas, empedrados de piedra y equipamiento, tanto educacional, como de salud y religioso, junto a una arquitectura de raigambre principalmente inglesa expresada en juegos volumétricos, bowindows, ventanas de guillotina, cornisas, zócalos y cenefas construidas en maderas nobles, cuya arquitectura, estilo y sistema constructivo logran constituir en estos cerros, un conjunto urbano y arquitectónicamente homogéneo, reconocible en la ciudad.

Paulatinamente en obras de envergadura y edificios relevantes se van incorporando refuerzos metálicos primeramente en sistema de rieles y hormigón en masa con estructuras de perfiles doble $\mathrm{T}$ tipo rieles, los que serán precursores del hormigón armado. Otras tipologías como edificios destinados a la habitación y comercio, incorporan las tabiquerías de madera rellena de adobillos generalmente en los segundos pisos, acogiendo sistemas de mayor flexibilidad ante movimientos telúricos (Jiménez y Ferrada, 2007).

En la arquitectura civil, a diferencia de la arquitectura religiosa, la concepción de las estructuras y los sistemas constructivos, deben supeditarse a las condicionantes urbanas, tales como la continuidad establecida para las fachadas en la línea de calle y a la conformación de los predios en que se emplazan, ya sea edificios manzanas, cruceros, cabezales o de forma rectangular dispuestos en forma transversal al mar y con frente a dos calles.

El planteamiento estructural de los edificios del plan de la ciudad, en este período, se basa en cimientos y sobrecimientos en subterráneos y zócalos con muros perimetrales de piedra que alcanzan 1,20 metros de espesor y gruesos muros de albañilería de ladrillo formando sistemas confinados y arriostrados (figura 14).

En general a fines de siglo XIX, los edificios logran una altura promedio de tres pisos y altillo, las albañilerías de ladrillo son utilizadas en muros perimetrales de los primeros pisos y cortafuegos. Las fachadas disminuyen su espesor en los pisos superiores, con tabiquería de madera rellenas con escoria o adobillos y revestidos con estucos de mortero que generan una apariencia similar al ladrillo estucado, que junto a los elementos de ornamentación propios del Historicismo ecléctico del período que caracterizó a Valparaíso en el siglo XIX, otorgan unidad al tratamiento de fachadas. Interiormente, como terminación las tabiquerías rellenas con adobillos, presentan mallas de alambre o ensordinados de álamo recubiertos de una argamasa de barro y paja, recibiendo finalmente un estuco de cemento o yeso. Los ornamentos son ejecutados 
FIGURA 14

TESTIMONIO ARQUITECTÓNICO: EDIFICIO PLAZA ECHAURREN

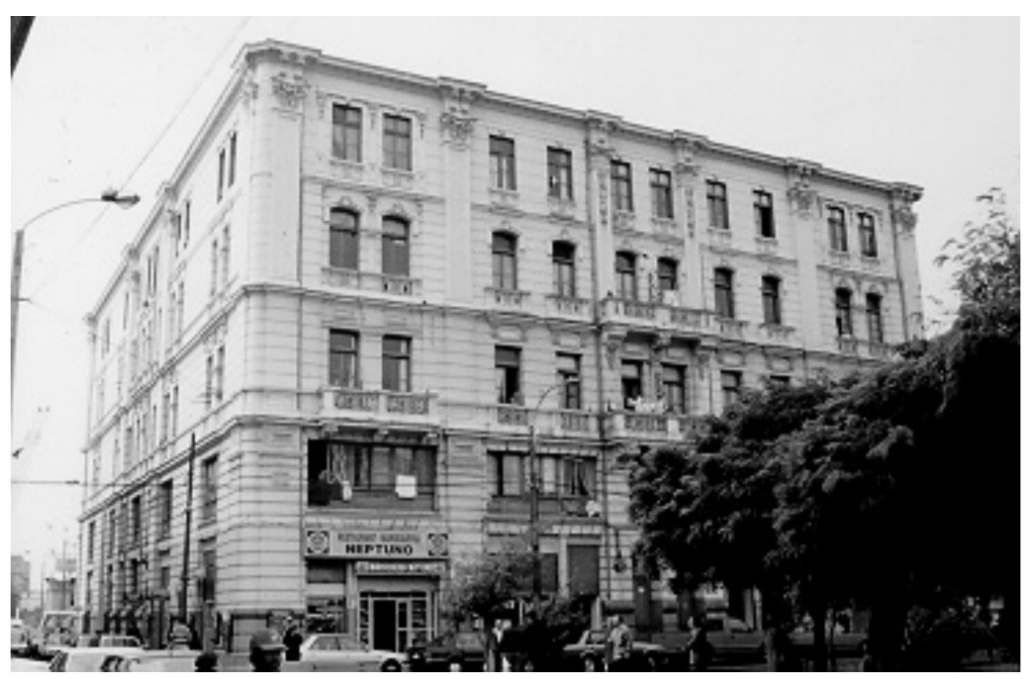

FIGURA 15

TESTIMONIO ARQUITECTÓNICO: EDIFICIO IVENS EN PLAZA ANIBAL PINTO-VALPARAÍSO

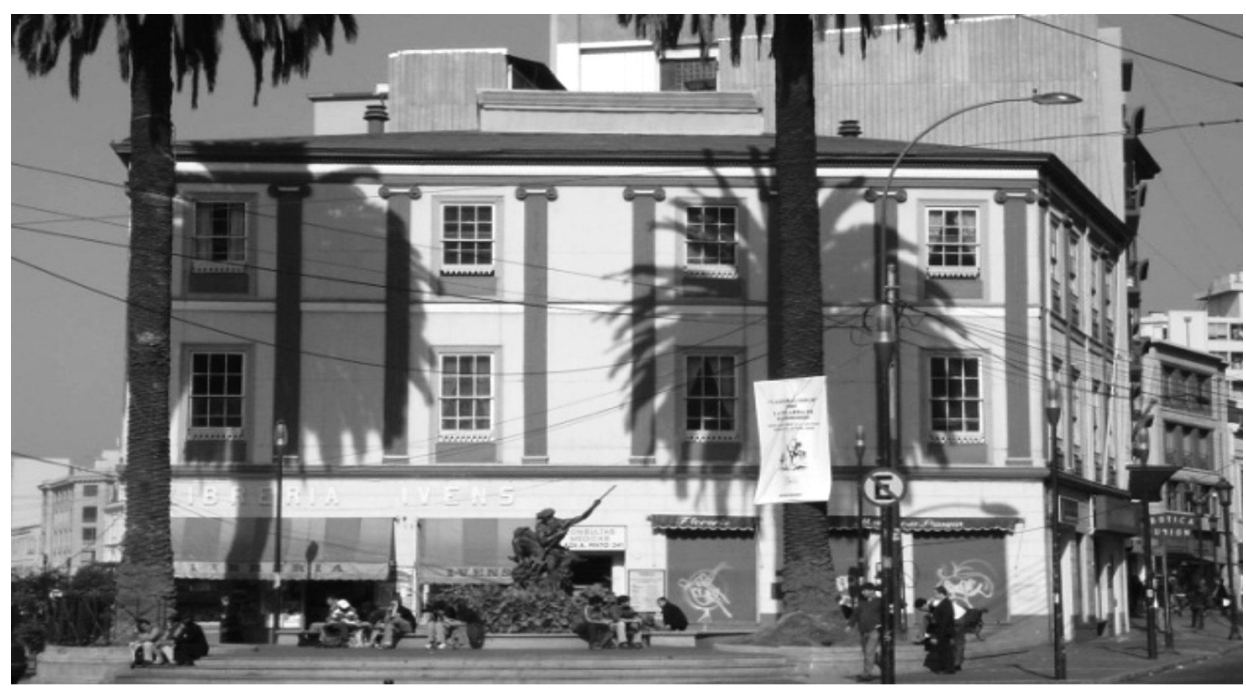

Estudios Geográficos, Vol. LXXII, 271, pp. 559-589, julio-diciembre 2011 ISSN: 0014-1496, eISSN: 1988-8546, doi: 10.3989/estgeogr.201122 
exteriormente con morteros de cemento e interiormente en yeso con elementos aglomerantes de tela o crin de caballo o malla de fierro sobre madera, con sujeciones metálicas empotradas a los muros.

Edificios construidos en el siglo XIX que aún permanecen en pie en el Área Histórica, dan cuenta de esta situación, como el edificio Ivens en la Plaza Aníbal Pinto (1854-1860) (figura 15).

Los muros perimetrales responden a sistemas rígidos cerrados conformados por albañilerías de ladrillo macizo, sin refuerzos, a diferencia de la estructura interior compuesta por entrepisos y tabiquería de maderas nobles, rellenas de adobillo. Complementa generalmente el sistema en los primeros pisos destinados a comercio, un reticulado interior de pilares metálicos de 4" de diámetro de alma llena, que soportan vigas maestras y que permiten disminuir las luces entre apoyos (Jiménez y Ferrada, 2003) (figura 16).

A finales de siglo xix e inicios del xx, Valparaíso recibe además las influencias de la revolución industrial en obras tan representativas como los ascensores urbanos, siendo el más antiguo el Ascensor Concepción construido en 1883, u obras de estructura metálica, como la Fábrica Ex Hucke en 1908 o el Mercado el Cardonal en 1912.

Además las influencias de la revolución industrial se expresan en obras tan representativas como los ascensores urbanos, siendo el más antiguo el Ascen-

FIGURA 16

EDIFICIO HUCKE

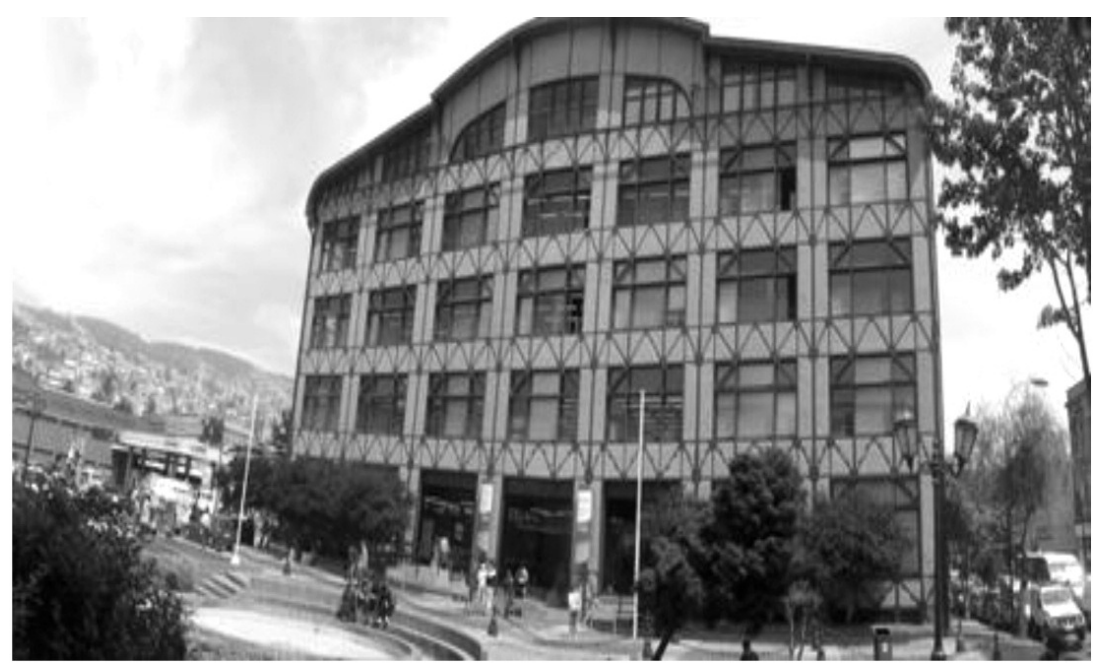

Estudios Geográficos, Vol. LXXII, 271, pp. 559-589, julio-diciembre 2011 ISSN: 0014-1496, eISSN: 1988-8546, doi: 10.3989/estgeogr.201122 
sor Concepción construido en 1883, u obras de estructura metálica, como la Fábrica Ex Hucke en 1908 o el Mercado el Cardonal en 1912.

A comienzos del siglo xx, el terremoto de 1906 en Valparaíso fue que marcó un hito en la historia de la ciudad, la que quedó devastada y donde murieron más de 3.000 personas. Este terremoto entregó grandes lecciones a los sistemas constructivos hasta ese momento utilizados y marca un hito de tal magnitud que puede apreciarse la diferencia de planteamiento usado por los profesionales frente al uso de materiales, sistemas constructivos y aún la concepción estructural en un mismo edificio construido por etapas, la primera antes del terremoto en albañilería de ladrillo y una segunda etapa en hormigón armado después del terremoto.

En consecuencia, a partir del terremoto de 1906 se incorpora definitivamente el hormigón armado como sistema estructural dando un salto cualitativo en la construcción en altura y salvando luces mayores, permitiendo espacios libres propios de la arquitectura historicista tardía en transición y la moderna propiamente tal, que comienza a desarrollarse en la ciudad.

Los efectos del sismo así como los festejos de celebración del primer centenario de la Independencia del país en 1910, constituyeron dos aspectos decisivos en la reconstrucción del Puerto de Valparaíso que puso a prueba el espíritu perseverante de sus habitantes, así también marcará un quiebre en la aplicación de los diversos sistemas constructivos utilizados hasta ese momento, pudiéndose apreciar en los edificios existentes estudiados, dos grandes tipologías constructivas, aquellos construidos antes y después de esta catástrofe, con algunas transiciones intermedias. Varias de estas iniciativas están aún en pie y han resistido los terremotos posteriores de los años 1965, 1971, 1985 y 2010, lo que demuestra el buen comportamiento estructural de estos edificios. En síntesis, el terremoto de 1906 sirvió de gran experiencia para los sistemas constructivos que hasta ese momento se utilizaban, para evolucionar definitivamente al hormigón armado apareciendo los primeros rascacielos en Valparaíso de ocho o más pisos (Jiménez y Ferrada, 2006) (ver figura 17).

En este marco, en el Valparaíso de hoy en el que se han asimilado las nuevas tecnologías y en el que priman las estructuras metálicas y el hormigón armado, adquieren mayor valoración lo inmuebles construidos en el siglo XIX que han sobrevivido al gran terremoto de 1906, con una clara lectura de las respuestas constructivas, frente a las condicionantes del período en que se construyeron, utilizando materiales existentes en la zona, y adaptándose a las particularidades que le impuso, las condiciones urbano-topográficas de su emplazamiento, demostrando un sabio manejo de los sistemas constructivos de la época con participación de obra de mano calificada y profesionales idó- 
FIGURA 17

TERREMOTO DE 1906

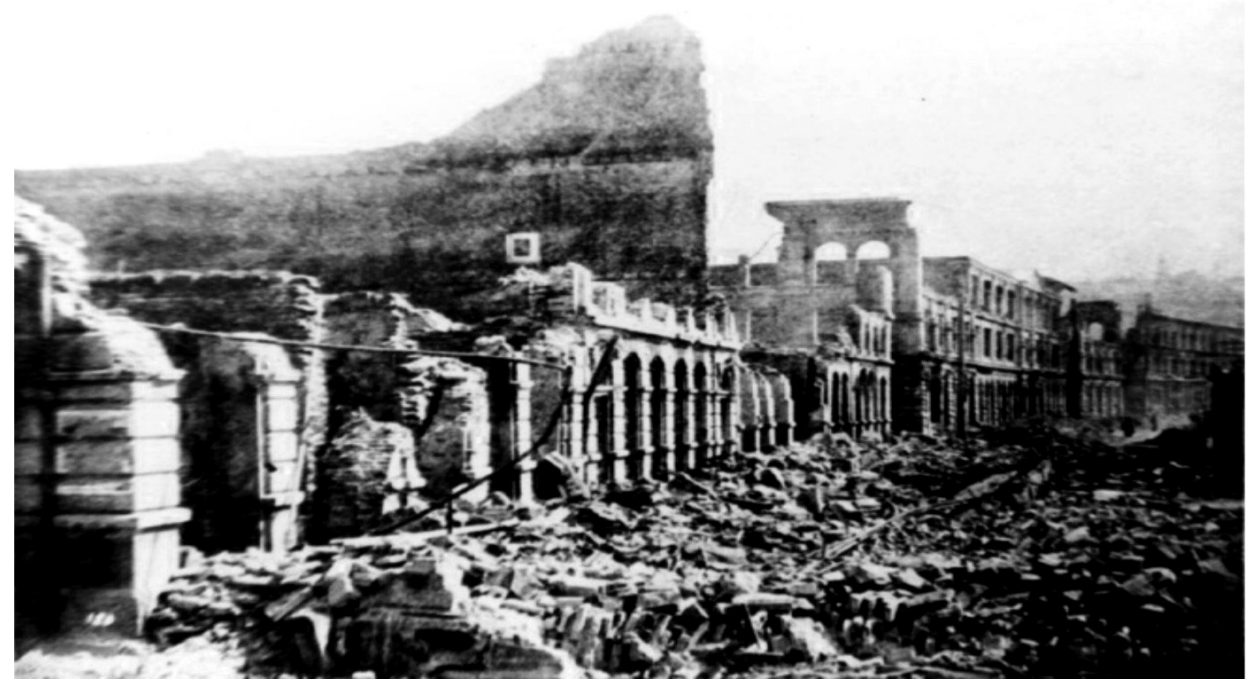

FIGURA 18

PLANO DEL SECTOR EL ALMENDRAL 1906

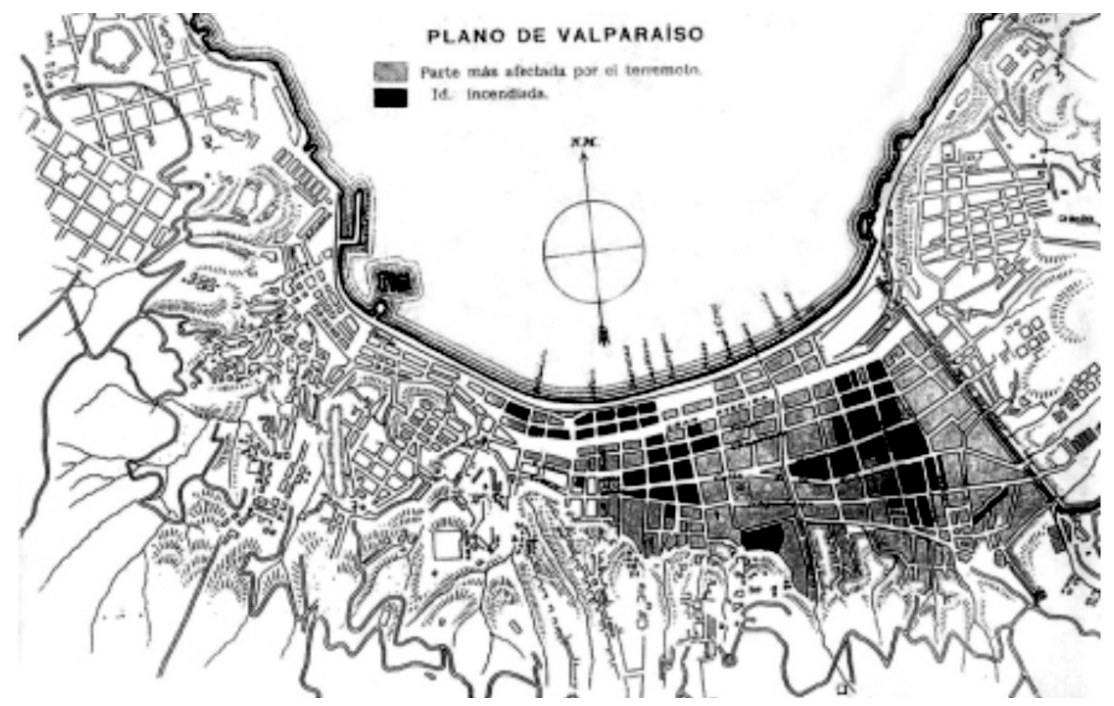

Estudios Geográficos, Vol. LXXII, 271, pp. 559-589, julio-diciembre 2011 ISSN: 0014-1496, eISSN: 1988-8546, doi: 10.3989/estgeogr.201122 
neos (Rodríguez y Gajardo, 1906). El terremoto que destruyó casi por completo la ciudad, modificó también el fondo de la bahía, en especial el barrio El Almendral (ver figura 18).

Esta arquitectura del siglo XIX que convive con arquitectura moderna y contemporánea, que se inserta en el anfiteatro natural de la ciudad con sus particularidades urbanas como su bahía, su trazado irregular, cerros, plazas pasajes, escaleras y ascensores, y que genera particulares respuesta a los diversos usos de la ciudad y aquellos en que los habitantes han puesto su propio sello, es la que ha sido reconocida por la UNESCO en el año 2003 con valores particulares, excepcionales que ameritaron su inclusión en la Lista del Patrimonio Mundial.

\section{CONCLUSiones}

1. La geografía cultural, como rama de la Geografía Humana, es una buena alternativa para analizar el paisaje natural donde la presencia de grupos sociales con sus técnicas, herramientas, instituciones y arquitectura, modifican el entorno de acuerdo a sus vivencias y costumbres. La ciudad de Valparaíso, por sus características puerto, ofrece las condiciones necesarias para un análisis de su emplazamiento, influencia arquitectónica aportada por sus inmigrantes, desarrollo comercial y la amenaza cíclica de los desastres naturales provocados por los sismos, todo esto bajo la denominación de ciudad Patrimonio de la Humanidad.

2. Localización, Emplazamiento e Identidad: En cuanto a su desarrollo, la ubicación estratégica de Valparaíso lo transformó en un puerto de primer orden en las rutas oceánicas hacia el resto del continente y al hemisferio Norte, se integra así a los más diversos mercados de la época. Transformándose a mediados del siglo XIX en el primer puerto del Pacífico Sur.

Por su emplazamiento, en parte sobre una antigua playa de arena, y por otra, cubierta por rellenos artificiales provenientes de escombros y sedimentos aportados por sus quebradas, está más expuesta a los efectos de los movimientos sísmicos.

La ciudad creció además, sin planificación previa hacia el mar y también de manera espontánea hacia los cerros generando una urbanización desordenada y heterogénea, siendo los fondos de quebradas las subidas naturales de accesos a la parte alta de la ciudad.

3. La influencia extranjera: La presencia británica contribuyó a la formación de un grupo empresarial nacional con dinámica que aportó su influencia 
en el crecimiento del país. El mejor ejemplo fue el desarrollo de la ciudad de Valparaíso, como un polo de la modernidad que se avecindaba en el país. En términos urbanos la ciudad de Valparaíso se vio invadida de una arquitectura, que aportaban los inmigrantes que se instalaban en la ciudad.

4. En términos urbanos, la ciudad de Valparaíso nació inicialmente entorno a los conjuntos religiosos y creció de manera espontánea hacia los cerros generando una urbanización heterogénea e irregular que sigue las leyes de la topografía, mientras que el borde se configura a través de sucesivos rellenos que culminaron a principios del siglo xx.

Los cerros Alegre y Concepción constituyen la primera ocupación planificada por los inmigrantes extranjeros, y ejemplo de las urbanizaciones en cuanto a provisión de agua potable, alumbrado a gas, pavimentos y equipamientos. Junto a lo anterior Valparaíso, recibió las influencias de una arquitectura historicista, aportada por los extranjeros, reconocible, particularmente en los cerros Alegre y Concepción, y en las que se aprecian muy buenos materiales y sistemas constructivos

5. Los sismos de alta intensidad que tienen una periodicidad cíclica afectan a la ciudad, provocan serios daños a su desarrollo y un grave deterioro al patrimonio construido, particularmente en los Monumentos Histórico religiosos de mediados y fines del siglo XIX.

Los efectos de los sismos marcaron un quiebre en la aplicación de diversos sistemas constructivos utilizados hasta ese momento. En efecto, los terremotos supusieron una gran lección a los sistemas constructivos que hasta ese momento se utilizaban, para evolucionar definitivamente al hormigón armado apareciendo los primeros rascacielos en Valparaíso de ocho o más pisos.

En este aspecto, se puede concluir que el Valparaíso de hoy, se han asimilado las nuevas tecnologías, donde priman las estructuras metálicas y el hormigón armado, adquieren mayor valoración lo inmuebles construidos en el siglo XIX que han sobrevivido al gran terremoto.

6. Lista del Patrimonio Mundial (2003): La arquitectura del siglo XIX que convive con la moderna y contemporánea, especialmente localizada en un anfiteatro natural con sus particularidades urbanas como su bahía, su trazado irregular, cerros, plazas pasajes, escaleras y ascensores, los que generan particulares respuesta a los diversos usos de la ciudad y aquellos en que los habitantes han puesto su propio sello y que recibió el reconocimiento de UNESCO.

Recibido: 11/07/2011

Aceptado: 22/09/2011 


\section{BIBLIOGRAFIA}

Aguirre, L (1946): El libro de Valparaíso. 1536-1946. Valparaíso, Esc. Tipográfica Salesiana.

Brignardello, T. et al. (1998): "Dinámica y caracterización espacial de la población del Gran Valparaíso". Revista de Geografía Norte Grande, 25, pp. 25- 31.

Cavieres, E. (1988): Comercio chileno y comerciantes ingleses 1820-1880: Un ciclo de Historia Económica. Valparaíso, Universidad Católica de Valparaíso.

Couyoumdjian, J. (2000): "El Alto Comercio de Valparaíso y las Grandes Casas Extranjeras, 1880-1930. Una aproximación". Historia, 33, pp. 63-99; doi: 10.4067/S0717-71942000003300002. Disponible en: http://www.scielo.cl/scielo. php? script=sci_arttext\&pid=S0717-71942000003300002\&lng=es\&nrm= iso\&tlng=es (consulta: 30/09/2011).

Couyoumdjian, J. (1986): Chile y Gran Bretaña durante la primera guerra mundial y la postguerra, 1914-1921. Santiago, Andrés Bello.

Edwards, J. (1963): Valparaíso. Santiago, Editorial Nacimento.

Escobar, A. (1926): El Príncipe de Gales en Chile. Homenaje de la Colonia Británica a SAR. Santiago, Imprenta y Litografía La Ilustración, 138 páginas.

Estrada, B. (1993): "Participación italiana en la industrialización de Chile. Orígenes y evolución hasta 1930", en B. Estrada (ed.): Presencia italiana en Chile. Valparaíso, Eds. Universitarias de Valparaíso, pp. 89-124.

Garreaud, J. (1984): "La formación de un mercado de tránsito. Valparaíso 18171848". Nueva Historia, 11, pp. 157-194. Disponible en: http://www.memoriachi lena.cl/archivos2/pdfs/MC0001481.pdf (consulta: 30/09/2011).

Graham, M. (1970): Diario de mi Residencia en Chile, 1822. Santiago, Editorial Universitaria.

Jiménez, C. (2000): "Identificación del Patrimonio Arquitectónico". Ciudad y Arquitectura, 101, pp. 38-45.

Jiménez, C. y Ferrada, M. (2003): "Los valores universales del patrimonio arquitectónico y urbano de Valparaíso". URBANO, 6/8, pp. 32-47. Disponible en http://re dalyc.uaemex.mx/src/inicio/ArtPdfRed.jsp?iCve=19800809 (consulta: 30/09/2011).

Jiménez, C. y Ferrada, M. (2006): "Hacia la determinación de una identidad arquitectónica en el Área Histórica de Valparaíso". Archivum, 6/7.

Jiménez, C. y Ferrada, M. (2007): "Identidad Arquitectónica heredada de fines de siglo XIX y comienzos del XX en el Área Histórica de Valparaíso. Proyecciones para su recuperación y desarrollo hacia el siglo XxI". Publicación derivada del Proyecto de Investigación DIPUV 47/04, Universidad de Valparaíso.

Lagos, R. (1966): La industria en Chile: antecedentes estructurales. Santiago, Universidad de Chile. 
Morton, W. H. (comp. y ed.) (1922): Enciclopedia Comercial. Único órgano oficial anual o bienal de la British and Latin American Chamber of Commerce. London, Globe Encyclopaedia.

Rodríguez, A. y Gajardo, C. (1906): La catástrofe del 16 de agosto de 1906 en la República de Chile. Santiago, Imp. Litografía y Encuadernación Barcelona.

Sánchez, A. (2003): Geografía de Chile. Santiago, Editorial Bibliográfica Internacional.

Sánchez, A., Bosque, J. y Jiménez, C. (2009): "Valparaíso: su geografía, su historia y su identidad como Patrimonio de la Humanidad". Estudios Geográficos, 266, pp. 269293.

Villalobos, S. (1986): El Comercio y la crisis colonial. Santiago, Universidad de Chile.

Waisberg, M. (1992): La arquitectura religiosa de Valparaíso. Santiago, Proyecto FONDECYT.

Waisberg, M. (1994): La traza urbana, patrimonio consolidado de Valparaíso. Buenos Aires, Fondo Nacional de la Artes.

Waisberg, M. (1996): "Arquitectos Europeos en el puerto de Valparaíso", en Autores Varios: De Toesca a la Arquitectura Moderna 1780-1950. Santiago, Centro de Arquitectura, Diseño y Geografía Universidad de Chile, pp. 95-105.

Waisberg, M. y Martínez, S. (1969): Los Terrenos del Antiguo Castillo de San José. Valparaíso, Área de Arte y Tecnología Universidad de Chile.

\title{
RESUMEN
}

Los procesos históricos, las condiciones geográficas de la ciudad y la condición sísmica del país, son los factores que han incidido directamente en la permanencia del patrimonio arquitectónico existente en la ciudad de Valparaíso, cuya Área Histórica ha sido incluida por UNESCO en la Lista del Patrimonio Mundial.

Los cíclicos y frecuentes fenómenos naturales (sismos y tsunamis) han configurado una geografía que revela una vulnerabilidad que afecta el paisaje y en lo humano pone en permanente riesgos el patrimonio cultural y la vida de su población.

Palabras Clave: patrimonio; geografía; construcción.

\begin{abstract}
Historical processes, Geographical conditions and seismical conditions are the prime factors that have directly determined the permanence of the architectural heritage in the City of Valparaíso, whose Foundational Area has been included by UNESCO in the World Heritage Roster.

Cyclical and frequent natural phenomena (seismic activity and tsunamis) have configured a Geography that exhibits the vulnerability of its natural landscape and the risks of its cultural heritage together with the lives of its population.
\end{abstract}

KEY WORDS: heritage; geography; building. 